The Price of Energy Efficiency in the Spanish Car Market

Ibon Galarraga

Ana Ramos

Josu Lucas

Xavier Labandeira 


\title{
The Price of Energy Efficiency in the Spanish Car Market
}

\author{
Ibon Galarraga a,b,d,, Ana Ramos c,d, Josu Lucas a , Xavier Labandeira c,d \\ a Basque Centre for Climate Change, Alameda de Urquijo 4, 48008 Bilbao, Spain \\ b University of the Basque Country (UPV-EHU), 48940 Leioa, Spain \\ ${ }^{c}$ Rede, Universidade de Vigo, Facultade de CC.EE., Campus As Lagoas s/n, 36310 Vigo, Spain \\ d Economics for Energy, Doutor Cadaval 2, 3E, 36202 Vigo, Spain
}

\begin{abstract}
Due to climate change, energy dependence and other energy-related issues, most developed countries are attempting to reduce fossil-fuel use in the transport sector. Accordingly, there are several instruments that have been in place for many years, such as mandatory design standards, taxes on fuels, car purchase and ownership, and energy efficiency labels. Yet it is still not clear whether consumers value energy efficiency as a characteristic of vehicles. In this paper we use the European labelling system for light vehicles, which classifies automobiles according to their relative fuel consumption levels, as a novel, alternative indicator for energy efficiency. Moreover, we use a unique database that incorporates official commercial prices along with prices obtained through 'mystery shopping' at a selection of Spanish car retailers. We apply the hedonic price method to this database to estimate the price functions for vehicles and thereby obtain the marginal price of high-rated vehicles in terms of energy efficiency. Our results show that automobiles labelled $A$ and $B$ are sold at prices 2.1 to 9.0 percent higher than those of vehicles with similar characteristics but lower energy-efficiency labels.
\end{abstract}

Keywords: Spain, transport, energy, efficiency, hedonic methods

JEL classification: Q41, Q48, R41

*Corresponding author ibon.galarraga@bc3research.org

Ibon Galarraga acknowledges the support of the Fundación Ramón Areces under the project PAEE (Políticas de apoyo a la eficiencia energética: impuestos vs subvenciones) and the REPSOL Foundation for its support through the Low Carbon Programme (www.lowcarbonprogramme.org), under which this work has been conducted. This paper was made possible by financial support from the Spanish Ministry of the Economy and Competitiveness through its research project EC02009-14586-C2-01 (Xavier Labandeira and Ana Ramos). The usual disclaimer applies. 


\section{Introduction}

The transport sector is responsible for more than 20 percent of the total greenhouse gas (GHG) emissions in the European Union, with roughly two thirds of that amount being caused by road transport (IPCC, 2007; EU, 2011). Transport also has significant local environmental impacts, with millions of citizens severely affected by air and noise pollution brought about by cars in both developed and emerging countries. Furthermore, the fact that this sector is a major consumer of energy and mostly relies on oil-related products has turned it into a preferential target for other environmental and energy-security policies [for instance, in 200797 percent of the final energy consumption of the Spanish transport sector was oil-related (Pérez and Monzón, 2008)].

However, despite significant policy efforts in this area in recent decades, resulting in a great many instruments and approaches, most developed and emerging countries have seen an increase in both vehicle numbers and the distances travelled by their occupants. Again in the case of Spain, the motorisation rate (number of vehicles per capita) grew from 0.32 to 0.48 in only twenty years (EU, 2011), while passenger cars continue to be the dominant option for land transport. It therefore seems that conventional policy instruments, mostly comprising mandatory design standards and taxes on fuels, car purchase and ownership, have been unable to cope with the growing size of the energy sector and with its ubiquitous energy and environmental problems (see e.g. Proost and Van Dender, 2012). Thus, there is growing interest among policymakers and other agents in the design and effects of different alternatives for tackling this problem.

In this context, there has been an increasing advocacy and implementation of information programmes in recent years. In particular, labelling and certification systems have sought to reduce market barriers such as incomplete information or bounded rationality, which prevent consumers from taking optimal decisions regarding energy efficiency. In particular, labelling systems for light-duty vehicles are intended to provide clear, accessible information to enable consumers to compare the fuel performances of similar vehicles. In the European Union (EU) this scheme is regulated by European Directive 1999/94/CE (European Commission, 2000), which requires Member States to impose a labelling system for light-duty vehicles that shows the absolute level of $\mathrm{CO}_{2}$ (carbon

dioxide) emissions and the fuel consumption of each new car when it is sold. Additionally, this 
Directive recommends the use of a voluntary label with differentiated energy-efficiency classes (from $A$ as the most energy efficient to $G$ as the least) that can facilitate comparisons between vehicles of the same size. The Spanish government transposed this mandate via Royal Decree 837/2002, which establishes that labels classify vehicles according to the difference between their own consumption levels and the average consumption of the group of the corresponding size. Average consumption is actually computed as follows:

$$
\text { average consumption }=a * e^{(b * S)}
$$

where $a$ and $b$ are parameters that must be reviewed and updated every year, and differ for gasoline and diesel cars. $S$ is vehicle size, measured as length by width. Appendix A shows the current Spanish labelling format.

Energy efficient labels thus represent a novel instrument well suited to analysing the purchasing decisions of consumers. In this sense, the hedonic price method has traditionally been a preferred approach for studying willingness to pay (WTP) for certain attributes of products, such as fuel economy or energy efficiency in the case of vehicles (Liu and Helfand, 2012). However, the interpretation of the regression coefficients is problematic due to the high degree of correlation that usually exists between the attributes of a product. That is why we believe that energy efficiency labels could be suitable for estimating the implicit price of fuel consumption. Additionally, the use of this indicator provides insights into whether or not there is a price premium associated with energyefficiency labels in vehicles, as has been suggested for other products such as buildings and household appliances. In particular, expected car fuel savings may be taken as a reference for such an analysis in the transport sector.

By using detailed data on car characteristics and prices, this study seeks to analyse the price effects of high-rated vehicles, in energy efficiency terms, on the Spanish market for new cars. The paper further contributes to the literature in this area via its use of retail prices as a better approximation to the real transaction price. To the best of our knowledge, previous research efforts using the hedonic approach have used official prices as those that lead to equilibrium in the market. However, there is casual evidence that, at least in the Spanish car market, retailers apply significant discounts on their 
own prices and thus the final price could be very different from the official one. To take this into account, our database consists of a sample of around 3,000 vehicle observations that provide detailed information on the characteristics and both the official and 'real' prices of cars. To anticipate the potentials and limitations of this approach and thus avoid the regulatory limitations of the past, it is particularly important to determine whether consumers value energy-efficiency characteristics when purchasing a new vehicle. Moreover, we compute an approximation to the present value of the fuel savings to determine whether Spanish consumers value energy efficiency rationally.

The rest of the paper is organised as follows. Section 2 reviews the literature to date in this field, and then briefly describes the hedonic pricing method and the data used. Section 4 presents and discusses the main results arising from the estimation of the model, and Section 5 compares the WTP of consumers with the present value of fuel savings and thus deals with the rationality of agents when purchasing energy-efficient vehicles. Finally, Section 6 summarises the main conclusions and implications of the paper.

\section{Literature}

Several papers have assessed the preferences of consumers regarding 'cleaner' cars through stated preferences. For instance Achtnicht (2012) estimates the WTP for cars with lower $\mathrm{CO}_{2}$ (carbon dioxide) emissions per $\mathrm{km}$, and finds that this is considered an important attribute by German car buyers, especially by women, older people and those with higher levels of education. Caulfield et al. (2010) focus on the car purchase decision to determine whether fuel costs and existing taxes influence the choices of Irish consumers. Ewing and Sarigöllü (2000) report a positive attitude towards clean cars among Canadian consumers due to their environmental benefits, even though they are unwilling to give up the customary levels of car performance. Baltas and Saridakis (2013) using compensatory choice modelling show that a number of variables, such as purpose of car use, prepurchase information sources, consumers predisposition towards buying an ecological car, or consumers involvement and attachment to cars, significantly affect the choice of car. 
Given the different characteristics or attributes of automobiles, consumers' preferences for cleaner cars could be also evaluated through revealed preferences, and particularly through the use of the hedonic pricing method. The first hedonic pricing studies for automobiles set out to establish a new method for computing price indices: the so-called 'quality-adjusted price index'. Given the technological advances in the automobile market, it was deemed necessary to differentiate price changes associated with changes in the quality of attributes from those made when all characteristics remained the same. Court $(1939)$ and Griliches $(1961,1964)$ first deal with this issue by presenting different models for computing adjusted-price indices for a period of time. More recently, this method has been used with the same purposes but with new model specifications by, for instance, Matas and Raymond (2009), Reis and Santos Silva (2002) and Izquierdo et al. (2001). Other authors employ the hedonic price method to estimate the implicit price of each car attribute, for instance energy efficiency or fuel economy (generally measured in miles per gallon). In particular, there is an initial group of papers that study the effects of gasoline price increases on the preferences of consumers for more energy-efficient cars after the oil crisis. In this context, Kahn (1986), Atkinson and Halvorsen (1984), Ohta and Griliches (1983) and Goodman (1983) focus mainly on used cars in the US, and find mixed results.

As observed in the introduction, interest in energy efficiency has undergone a revival in practical and academic terms in the last few years, largely due to energy dependency and environmental and climate change concerns. In this sense, Chugh et al. (2011) use the hedonic pricing method to test the hypothesis that Indian consumers rationally value fuel economy by comparing the marginal price of fuel economy with the present value of fuel savings. To avoid correlation with unobservable variables, they use ordinary least squares (OLS) and instrumental variables (IV) with average fuel economy (in miles per gallon) of the same car brand as the instrument for fuel economy. Their results from IV show an implicit price of fuel economy that ranges from 1 to 10 percent of the total price in the period from 2002 to 2006 which, compared to the present value of energy savings, does not support undervaluation of the fuel economy of cars. Kiso (2010), on the other hand, applies an alternative hedonic model to 2001 US data on new vehicles to avoid omitted variable bias. Using data on gasoline prices and the estimated miles travelled per year, the paper constructs a proxy for the marginal price of fuel economy, which is shown to be between 5 and 10 percent of the retail price. Moreover, as expected, the paper reports a higher cost of fuel economy in larger vehicles. Also using 
data from the US new vehicle market in the same year, Espey and Nair (2005) estimate four models with OLS using different specifications of fuel economy. Although their results coincide with Chugh et al. (2011) in that WTP for more fuel-efficient vehicles exceeds energy savings, they suggest that buyers behave rationally because the difference is explained by the environmental and energy concerns of consumers. Yet, by contrast with to the aforementioned papers, Arguea and Hsiao (1993) find mixed evidence of car price increases associated with more mileage per gallon in 19691986.

In this paper we follow a similar hedonic approach to estimate the implicit price of fuel consumption or energy efficiency, using the EU labelling system as an indicator for fuel economy that avoids problems associated with multicollinearity and omitted variables. To the best of our knowledge, the only piece of research that evaluates the WTP for energy-efficient vehicles through labelling is an ongoing research project by Alberini et al. (2013) that considers the Swiss car rating system.

\section{Estimation}

\subsection{Hedonic price model}

The hedonic price method is based on the assumption that a product can be represented as a vector containing its characteristics or attributes. By extension, the price of that product can be expressed as a function of the attributes

$$
P(z)=p\left(z_{1}, z_{2}, \ldots, z_{n}\right)
$$

where $z_{i}$ etc. represent each of the attributes of the good. In equilibrium, the price of each attribute is equal to the cost for the manufacturer of producing that characteristic (Court, 1939; Griliches, 1961; Rosen 1974). Therefore, in a competitive equilibrium the hedonic price method enables the implicit price of each characteristic of a vehicle to be estimated. It is given by the partial derivative of the

vehicle price function with respect to each attribute. Thus, $\frac{\partial \mathrm{P}(\mathrm{z})}{\partial \mathrm{z}_{\mathrm{i}}}$ reports consumers' WTP for an extra unit of the attribute $z_{i}$ or, similarly, the manufacturer's marginal cost of producing such an additional 
unit. Although this approach bases its conclusions on real transaction prices, given the difficulties of using that price researchers have tended to use manufacturers' official prices as an approximation to the transaction price. As indicated above, however, the two prices do not necessarily coincide. Therefore, we propose the use of commercial retail prices as a more adequate approximation to the transaction price.

\subsection{The data}

We employ a database developed especially for this study with micro-information on more than 3,000 observations of low, medium and high range vehicles on sale in Spain. Each automobile is identified by its unique model description in the database, which allows us to match different data sources to collect a detailed set of information. For instance, we have information on the type of car fuel, size, horsepower, extra equipment, brand, number of seats, fuel consumption, etc. (see Appendix B for a full list of the characteristics contained in the database). The main advantage of this database over those used in previous research efforts in this area is the inclusion of data on both the manufacturer's official prices and actual retail prices. This means that when applying the hedonic price method two sources of prices can be used that should be very close to equilibrium prices. Data on official prices and on vehicle characteristics are taken from specialist car magazines and official car makers' websites, while a subsample of retailer prices, containing 372 observations, was gathered by survey company CDS, Estudios de Mercado y Opinión S.L. using the so-called 'mystery shopping' approach ${ }^{1}$. Retail prices were surveyed for the 15 most representative brands at different authorised dealers throughout Spanish territory². Moreover, to avoid market changes, all prices were gathered between September and November 2012.

The official prices obtained included only value added tax (VAT), while the retail prices also included vehicle registration taxes ${ }^{3}$ and retailers' management costs, so price homogenization was required. To that end we subtracted the corresponding registration tax and the average retailers' management

\footnotetext{
1 This method can obtain reliable information on a specific service or product, gathered by an agent who pretends to be a normal consumer.

2 Surveys were carried out in a selection of the most representative Spanish mainland regions: Andalusia, Catalonia, Basque Country, Galicia and Madrid.

3 Vehicle registration taxes depend on $\mathrm{CO}_{2}$ emissions in Spain.
} 
costs from the retail prices. As a final step, each observation was matched with its corresponding energy-efficiency label using information provided by IDAE (Spanish Institute for Energy Diversification and Savings). In fact, IDAE has developed a database with data on $\mathrm{CO}_{2}$ emissions, consumption and the corresponding energy-efficiency label for each model of vehicle sold in Spain 4 . Energy labels classify each vehicle based on the difference between its fuel consumption and the average consumption by cars of a similar size. This has allowed us to match each vehicle with its corresponding label to obtain a database with all the relevant characteristics needed to estimate the price function.

Table 1 describes the most relevant variables of the database built for this study. First of all, the survey to collect the retail prices deals with 71.5 percent of the car models and shows no major differences compared with the full sample, thus demonstrating that the reduced sample represents the entire market quite well. Both samples suggest that most vehicles on sale in Spain are small and medium sized, and that gasoline and diesel engines account for more than the 90 percent of the fleet. The supply of automobiles also shows a high level of energy efficiency, with 36 percent of vehicles labelled as $B$ and also a fairly large number with $A$ and $C$ labels. Thus, if label $D$ is set as the benchmark for average energy efficiency, more than 60 percent of the vehicles on sale in Spain are energy-efficient. Finally, the bottom lines of Table 1 report some statistics on the main variables contained in the database. Importantly, as expected, the average retail prices are lower than the average official prices by around 3,000 Euros, which suggests that retailers adapt official prices according to their own commercial strategies. This vindicates our approach.

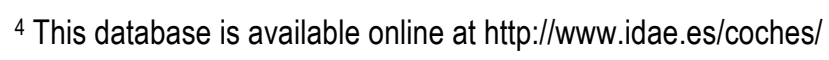


Table 1. Description of the database

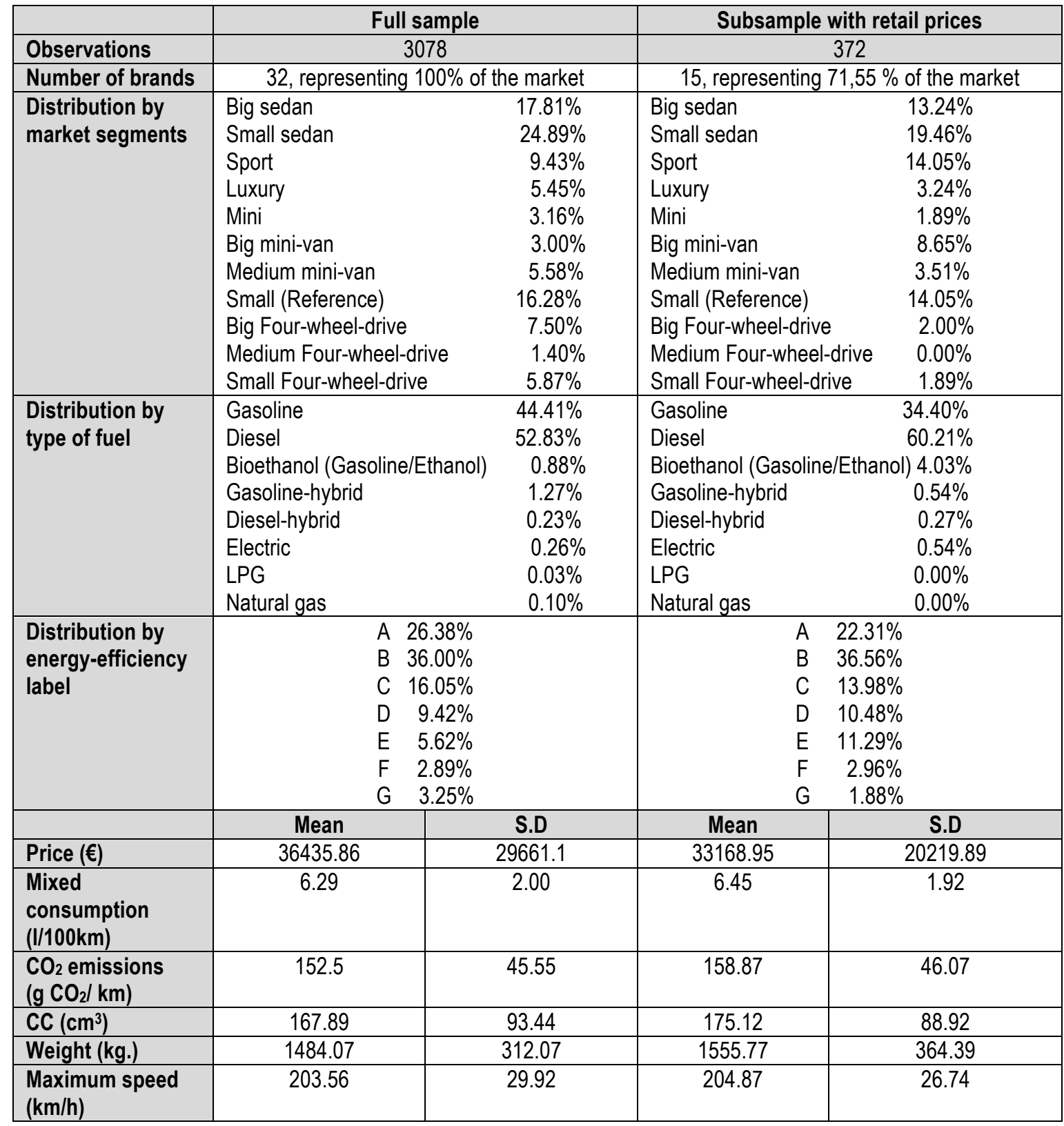

Source: The authors

\subsection{The regression model}

Since the number of non-gasoline/diesel cars in our database is almost negligible and energy efficiency labels do not have any effect on alternatives such as gas-fuelled or electric vehicles, we restrict our estimation to gasoline and diesel cars. As customary in this field we use a semi-log model 
for the price function of vehicles (Equation 2), which is estimated using the official and retail price samples separately.

$\ln \left(p_{i}\right)=\alpha+\beta A B_{i}+\delta_{1}$ weight $_{i}+\delta_{2} C C_{i}+\delta_{3} R P M_{i}+\delta_{4}$ maxspeed $_{i}+\delta_{5}$ acel $_{i}+\delta_{6}$ cap $_{i}+$ $\gamma_{1} D_{1, i}+\sum_{c=1}^{11} \gamma_{2 c} D_{2, i c}+\sum_{n=1}^{32} \gamma_{3 n} D_{3, i n}+\sum_{s=1}^{7} \gamma_{4 s} D_{4, i s}+\sum_{a=1}^{5} \gamma_{5 a} D_{5, i a}+\sum_{m=1}^{4} \gamma_{6 m} D_{6, i m}+$ $\sum_{t=1}^{3} \gamma_{7 t} D_{7, i t}+\sum_{e=1}^{6} \gamma_{8 e} D_{8, i e}+\varepsilon_{i}$

The dependent variable in Equation 2 is the logarithm of the price for observation $i$, with $\alpha$ as the constant of the model. To estimate the price effects of labelling we first attempted to use a discrete variable for the levels of each label. However, using the statistic variance inflation factor (VIF), which measures the correlation between explanatory variables (Wooldridge, 2009), we found high levels of multicollinearity that affected the coefficients of the label variables. Therefore we created a dummy variable $(A B)$, valued at one if the car has a class $A$ or $B$ label and zero otherwise, which does not suffer from multicollinearity. Hence, the coefficient of interest in equation (2) is $\beta$, which measures the marginal price of energy efficiency (defined as having $A$ or $B$ labels). Even though labels are a function of size, their effect would be overestimated if we did not control for the increase in price due to larger vehicles. Thus, we use weight (in tonnes) as a proxy for the length and width of the car. We also include the variables CC, RPS, maxspeed, acel and cap for cubic centimeters (measuring engine size), revolutions per second, maximum speed, acceleration and boot capacity (in 100l) respectively. Finally, Equation 2 contains dummies for the type of fuel (D1), commercial vehicle segment $(D 2)$, market brands (D3), number of seats (D4), number of airbags (D5), number of gears in manual gearboxes, including automatic transmission (D6), type of drive system (D7) and six dummies for extra equipment (D8), all described in full in Appendix B. We believe that this extensive set of characteristics and the use of labels as an indicator of energy efficiency will enable the coefficient for energy efficiency to be interpreted correctly.

Two additional model specifications are implemented to check the results: the first replaces the variable $A B$ by fuel consumption (in l/km), whereas the second uses a new dummy variable instead of $A B$, called $A$, which takes a value of 1 if the vehicle has a class $A$ label and 0 otherwise. Although the first of these alternatives might result in multicollinearity, the objective is to use two similar indicators of energy efficiency to validate our results. We would expect the coefficient for fuel 
consumption to have a similar magnitude but the opposite sign to the coefficient for $A B$, while the coefficient for $A$ should have the same sign but a larger magnitude than $A B$ due to the exclusion of the effect of label $B$ from the combined effect. Finally, we regress the original model separately for each commercial segment so that we can identify differences in WTP depending on the type of vehicle. Since each commercial segment is determined by its own characteristics, we expect different implicit prices for energy efficiency.

\section{Results}

Table 2 displays the results for the estimation of Equation 2. Column 2 depicts the results using official prices, whereas column 6 shows the results with retail prices (columns 3 and 7 are the corresponding standard errors). Most coefficients are significant, and have the expected sign in both models. The R-squared, moreover, suggests that most price variability is explained by the model. The main objective of this research was to estimate the marginal effect of high-rated vehicles, which is explained by the coefficient of variable $A B$. In fact, both models suggest that energy-efficient vehicles (those with class $A$ and $B$ labels) are more expensive than the rest. In particular, all other variables being equal, the amounts associated with energy-efficient vehicles are 1.3 and 9.04 percent of the price for official and retail prices, respectively. Moreover, our results indicate that consumers value-energy efficient vehicles, that is, that they are willing to pay more for vehicles with $A$ or $B$ labels.

However, there is a substantial difference between the figures of the two results. This might be partially explained by the type of observations included in each sample: the sample with retail prices contains only observations for the 15 best-selling brands on the Spanish market, while the official price sample contains all the models available on that market. The latter includes several luxury brands that provide vehicles with clearly distinctive characteristics that could be biasing the results if the dummy for luxury is unable to control their full effect. Consequently, we re-estimated the model using official prices but considering only the 15 best-selling brands in Spain. Column 4 in Table 2 reports the corresponding results: basically the coefficient of interest for official prices, $\beta$, increases to 2.1 percent. The remaining difference could be due to the origin of the prices: official prices are 
supply-side prices, while retail prices are closer to being demand-side prices (i.e. are prices at equilibria and thus better incorporate demand factors). This could indicate that consumers value energy efficiency more highly than producers.

Table 2. Estimated results for vehicles labelled as A or B

\begin{tabular}{|c|c|c|c|c|c|c|}
\hline & $\begin{array}{l}\text { Official prices } \\
\text { Full sample }\end{array}$ & & $\begin{array}{l}\text { Official prices } \\
\text { Reduced } \\
\text { sample }\end{array}$ & & Retail prices & \\
\hline & Coefficient & S.D & Coefficient & S.D & Coefficient & S.D \\
\hline Gasoline & $-0.0565^{\star * *}$ & $(0.00941)$ & $-0.0601^{* * *}$ & $(0.0104)$ & $-0.0930^{*}$ & $(0.0292)$ \\
\hline CC & $0.00265^{* * *}$ & $(8.15 \mathrm{e}-05)$ & $0.00260^{* * *}$ & $(7.70 \mathrm{e}-05)$ & $0.00302^{* * *}$ & $(0.000268)$ \\
\hline RPS & $-0.00065^{* *}$ & $(0.00031)$ & $-0.00037^{* *}$ & $(0.000336)$ & $-0.00334^{* * *}$ & $(0.00128)$ \\
\hline Maxspeed & $0.00110^{* * *}$ & $(0.000318)$ & $0.000696^{\star *}$ & $(0.000281)$ & 0.000334 & $(0.000775)$ \\
\hline Acel & 0.000795 & $(0.00167)$ & -0.000338 & $(0.00168)$ & 0.00921 & $(0.00754)$ \\
\hline$A B$ & $0.0135^{\star \star}$ & $(0.00606)$ & $0.0210^{* * *}$ & $(0.00702)$ & $0.0904^{* * *}$ & $(0.0292)$ \\
\hline Weight & $0.36532^{* * *}$ & $(0.02341)$ & $0.43968^{* * *}$ & $(0.02737)$ & $0.226^{* * *}$ & $(0.0948)$ \\
\hline Cap & 0.00169 & $(0.00279)$ & $-0.00589^{* *}$ & $(0.00256)$ & $-0.0186^{* *}$ & $(0.00897)$ \\
\hline Automatic & $0.0620 * * *$ & $(0.00900)$ & $0.0755^{* * *}$ & $(0.0103)$ & $0.117^{\star *}$ & $(0.0477)$ \\
\hline $\mathrm{A} / \mathrm{C}$ & $0.0401^{* * *}$ & $(0.00816)$ & $0.0354^{* * *}$ & $(0.0104)$ & $0.106^{* * *}$ & $(0.0278)$ \\
\hline Constant & $8.818^{* * *}$ & $(0.0783)$ & $8.831^{* * *}$ & $(0.0764)$ & $9.098^{* * *}$ & $(0.232)$ \\
\hline Dummy for brand & $Y$ & & $\mathrm{Y}$ & & $\bar{Y}$ & \\
\hline $\begin{array}{l}\text { Dummy for } \\
\text { commercial } \\
\text { segment }\end{array}$ & Y & & $Y$ & & $Y$ & \\
\hline $\begin{array}{l}\text { Dummy for extra } \\
\text { equipment }\end{array}$ & $Y$ & & $Y$ & & Y & \\
\hline Dummy for \#seats & Y & & $Y$ & & Y & \\
\hline $\begin{array}{l}\text { Dummy for } \\
\text { \#airbags }\end{array}$ & Y & & $Y$ & & Y & \\
\hline $\begin{array}{l}\text { Dummy for } \\
\text { traction type }\end{array}$ & $Y$ & & $Y$ & & $Y$ & \\
\hline $\begin{array}{l}\text { Dummy for } \\
\text { \#speeds }\end{array}$ & Y & & $Y$ & & Y & \\
\hline Observations & 2,961 & & 2,124 & & 352 & \\
\hline R-squared & 0.965 & & 0.970 & & 0.978 & \\
\hline
\end{tabular}

Note: Robust standard errors in parentheses ${ }^{* * *} p<0.01,{ }^{* *} p<0.05,{ }^{*} p<0.1$

Source: The authors.

In short, our results not only provide the first empirical evidence of the WTP for energy-efficient vehicles among Spanish consumers but also contribute to the international literature in this area, yielding values that fall within the usual range found in evidence to date. The results for the rest of the variables are as expected and are very similar for the two price specifications: gasoline vehicles are 6 to 9 percent cheaper than diesel, engine size (measured in cubic centimeters $(C C)$ ), weight and maximum speed (maxspeed) increase prices in the regression of official prices. Table 2 also displays 
the marginal cost of some of the dummies included in the model, such as air conditioning and automatic transmission relative to conventional five-speed gearboxes.

Table 3 shows results for the first alternative model, which uses fuel consumption as an indicator of energy-efficiency. Most of the coefficients remain unchanged in the two samples when variable $A B$ is replaced by fuel consumption in the reduced official-price sample. The coefficient for fuel economy does not have the expected sign in the official-price sample because, all else being equal, an increase in fuel consumption should decrease the WTP. However, this is not the case in the retailprice sample, in which the value assigned to fuel consumption not only has a negative sign but is on the same order of magnitude as in previous results. Again, this difference could be explained by the source of the prices: an increase in fuel consumption in $1 / \mathrm{km}$ is an undesirable characteristic for consumers, but it might not be so for producers. The fact that the implicit price of fuel consumption is lower than the price for high-rated vehicles could indicate that there is a price premium associated with labels, as mentioned above. Finally, the VIF shows a higher level of multicollinearity for the coefficient for fuel consumption than the $A B$ coefficient.

Table 4 displays the results for the second alternative specification, which replaces the variable $A B$ by the variable $A$ (for vehicles labelled as $A$ ). In this case, as expected, the coefficient for $A$ is higher than the coefficient for $A B$ in both models. This regression shows the robustness of our results to alternative model specifications: The WTP of consumers for vehicles labelled $A$ is again higher than for those labelled $\mathrm{A}$ or $\mathrm{B}$. 
Table 3. Estimated results for vehicles' fuel consumption (in I/100km.)

\begin{tabular}{|c|c|c|c|c|}
\hline & $\begin{array}{l}\text { Official } \\
\text { reduced }\end{array}$ & $\begin{array}{l}\text { prices } \\
\text { sample }\end{array}$ & Retail & prices \\
\hline & Coefficient & S.D & Coefficient & S.D \\
\hline Gasoline & $-0.0823^{\star * \star}$ & $(0.0134)$ & -0.0510 & $(0.0518)$ \\
\hline & $0.00241^{* * *}$ & $(7.86 \mathrm{e}-05)$ & $0.00312^{* * *}$ & $(0.000280)$ \\
\hline RPS & -0.000371 & $(0.000330)$ & -0.00228 & $(0.00140)$ \\
\hline Maxspeed & $0.000702^{* * *}$ & $(0.000264)$ & 0.000106 & $(0.000779)$ \\
\hline & -0.000556 & $(0.00166)$ & 0.00238 & $(0.00842)$ \\
\hline Consumption & $0.0131^{* \star \star}$ & $(0.00404)$ & $-0.0307^{\star *}$ & $(0.0146)$ \\
\hline Weight & $0.399^{* * *}$ & $(0.0283)$ & $0.285^{* \star *}$ & $(0.0995)$ \\
\hline & $-0.00424^{*}$ & $(0.00248)$ & $-0.0195^{\star \star}$ & $(0.00884)$ \\
\hline aut & $0.0742^{* * *}$ & $(0.0103)$ & $0.118^{* *}$ & $(0.0462)$ \\
\hline & $0.0372^{* * *}$ & $(0.0104)$ & $0.101^{* * *}$ & $(0.0290)$ \\
\hline Constant & $9.091^{* * *}$ & $(0.0760)$ & $9.511^{\star * *}$ & $(0.226)$ \\
\hline Dummy for brand & $\mathrm{Y}$ & & $\mathrm{Y}$ & \\
\hline $\begin{array}{l}\text { Dummy for } \\
\text { commercial } \\
\text { segment }\end{array}$ & $\mathrm{Y}$ & & $\mathrm{Y}$ & \\
\hline $\begin{array}{l}\text { Dummy for extra } \\
\text { equipment }\end{array}$ & Y & & Y & \\
\hline Dummy for \#seats & Y & & Y & \\
\hline Dummy for \#airbags & Y & & Y & \\
\hline $\begin{array}{l}\text { Dummy for traction } \\
\text { type }\end{array}$ & Y & & Y & \\
\hline $\begin{array}{l}\text { Dummy for \#speeds } \\
\text { Observations } \\
\text { R-squared }\end{array}$ & $\begin{array}{l}2,122 \\
0.970\end{array}$ & & $\begin{array}{c}352 \\
0.978\end{array}$ & \\
\hline
\end{tabular}

Robust standard errors in parentheses ${ }^{* * *} p<0.01,{ }^{* *} p<0.05,{ }^{*} p<0.1$

Source: The authors. 
Table 4. Estimated results for vehicles labelled as $\mathrm{A}$

\begin{tabular}{|c|c|c|c|c|}
\hline & $\begin{array}{l}\text { Official } \\
\text { reduced }\end{array}$ & $\begin{array}{c}\text { prices } \\
\text { samples }\end{array}$ & Retail & prices \\
\hline & Coefficient & S.D & Coefficient & S.D \\
\hline Gasoline & $-0.0642^{* * *}$ & $(0.0103)$ & $-0.151^{\star * *}$ & $(0.0523)$ \\
\hline CC & $0.00259^{* * *}$ & $(7.39 \mathrm{e}-05)$ & $0.00266^{* * *}$ & $(0.000236)$ \\
\hline RPS & -0.000254 & $(0.000331)$ & -0.000869 & $(0.00133)$ \\
\hline Maxspeed & $0.000729^{\star \star *}$ & $(0.000277)$ & 0.00114 & $(0.000766)$ \\
\hline Acel & -0.000998 & $(0.00165)$ & $0.0134^{*}$ & $(0.00728)$ \\
\hline & $0.0464^{\star \star \star}$ & $(0.00550)$ & $0.146^{\star \star *}$ & $(0.0276)$ \\
\hline Weight & $0.440^{\star \star \star}$ & $(0.0272)$ & $0.206^{\star \star}$ & $(0.0906)$ \\
\hline Cap & $-0.00657^{* * *}$ & $(0.00254)$ & -0.0132 & $(0.00801)$ \\
\hline Aut & $0.0738^{* * *}$ & $(0.0101)$ & $0.157^{* * *}$ & $(0.0476)^{\prime}$ \\
\hline & $0.0322^{* * *}$ & $(0.0102)$ & $0.0668^{* *}$ & $(0.0299)$ \\
\hline Constant & $8.838^{* \star *}$ & $(0.0745)$ & $8.867^{* * *}$ & $(0.204)$ \\
\hline $\begin{array}{l}\text { Dummy for } \\
\text { brand }\end{array}$ & $\mathrm{Y}$ & & $Y$ & \\
\hline $\begin{array}{l}\text { Dummy for } \\
\text { commercial } \\
\text { segment }\end{array}$ & Y & & $Y$ & \\
\hline $\begin{array}{l}\text { Dummy for } \\
\text { extra } \\
\text { equipment }\end{array}$ & $Y$ & & $Y$ & \\
\hline $\begin{array}{l}\text { Dummy for } \\
\text { \#seats }\end{array}$ & $Y$ & & $Y$ & \\
\hline $\begin{array}{l}\text { Dummy for } \\
\text { \#airbags }\end{array}$ & $Y$ & & $Y$ & \\
\hline $\begin{array}{l}\text { Dummy for } \\
\text { traction type }\end{array}$ & $Y$ & & $Y$ & \\
\hline $\begin{array}{l}\text { Dummy for } \\
\text { \#speeds }\end{array}$ & $Y$ & & $Y$ & \\
\hline Observations & 2,124 & & 352 & \\
\hline R-squared & 0.971 & & 0.980 & \\
\hline
\end{tabular}

Finally, using the full official-price sample, Table 5 reports WTP results for A-labelled vehicles in each commercial segment. A priori, one would expect bigger vehicles with higher fuel consumption to have the highest energy-efficiency implicit price, as the expected fuel savings are larger. However, our results do not support this hypothesis: the sports and luxury segments show the largest WTP for vehicles labelled as A, but the coefficient for energy efficiency is not statistically significant for SUVs, the other segment with high consumption. Cars in the small category show the second highest WTP 
for energy efficiency, followed by minivans and sedans. Hence, our estimates do not indicate a clear link between the commercial segment of vehicles and WTP for energy efficiency.

Table 5. Estimated results in each commercial segment (using vehicles labelled A)

\begin{tabular}{c|cccccc}
\hline & Sedan & $\begin{array}{c}\text { Sport \& } \\
\text { Luxury }\end{array}$ & Mini & Small & Minivan & $\begin{array}{c}\text { Four-wheel-drive } \\
\text { (SUV) }\end{array}$ \\
\hline \hline Coef. (A) & $0.0116^{* *}$ & $0.0619^{* * *}$ & 0.0196 & $0.0403^{* * *}$ & $0.0322^{* *}$ & 0.0438 \\
S.D. & $(0.00535)$ & $(0.0200)$ & $(0.0165)$ & $(0.0105)$ & $(0.0156)$ & $(0.0276)$ \\
\hline
\end{tabular}

Robust standard errors in parentheses ${ }^{* * *} p<0.01,{ }^{* *} p<0.05,{ }^{*} p<0.1$

Source: The authors.

\section{WTP for energy efficiency and present value of fuel savings}

Once the WTP for energy-efficient vehicles is known, it can be compared with the present value of fuel savings associated with such vehicles. Indeed, if consumers behave rationally one could argue that their WTP for energy-efficient vehicles should be close to the energy savings attainable during the lifetime of the vehicle. A detailed analysis of this issue, incorporating expected fuel prices, lies beyond the scope of this research, but a rough calculation could provide another robustness check for our results, besides obtaining some insights into the behaviour of Spanish consumers in this area. This comparison is depicted in Table 6.

Table 6. WTP for and savings from energy efficient vehicles

\begin{tabular}{cc|c|c}
\hline Discounted fuel savings & $\begin{array}{l}\text { WTP for a vehicle labelled A, } \\
\text { using the average price for the } \\
\text { official-price subsample }\end{array}$ & $\begin{array}{l}\text { WTP for a vehicle labelled A, } \\
\text { using the average price for the } \\
\text { retail-price sample }\end{array}$ \\
\hline \hline$r=5 \%$ & $2,248.04$ Euros & 1690.62 Euros & 5273.85 Euros \\
\hline$r=10 \%$ & $1,841.61$ Euros & & \\
\hline$r=15 \%$ & $1,551.34$ Euros & & \\
\hline
\end{tabular}
Source: The authors.

Previous research has found mixed evidence concerning the rationality of consumers' WTP for energy-efficient vehicles (see Section 2). As an approximation to this matter, in Table 6 we use data on annual household expenditures on fuel and lubricants from the Spanish Institute for Statistics 
(INE). The figure is for 2012 is 1030 Euros. Given that vehicles with class A labels consume 25 percent less than those with class $D$, taken as a reference, we observe that the expected energy savings over a vehicle lifetime of 10 years range from 2248.04 to 1551.34 Euros, using discount rates from 5 to 15 percent respectively. These expected energy savings are checked against the WTP obtained from our alternative regression using the dummy for vehicles labelled as $\mathrm{A}$.

By employing two price approximations as boundaries, we obtain several interesting results. For the retail price sample, the WTP exceeds the present value of fuel savings, independently of the discount rate. Although this finding coincides with the results of Chugh et al., (2011) and Espey and Nair (2005), given the magnitude of the difference between the two values it could be reflecting an overestimation of the WTP when retail prices are used. Other explanations might be worth considering to unravel this issue in future research. The impact of commercial strategies of dealers might be playing a significant role in the car market in Spain. And thus, supply side factors are prevailing when retail prices are considered. In this sense, Van der Vooren et al. (2013) offer some insights regarding such supply-side effects, showing how the product portfolio of Dutch firms has changed due to energy labelling.

On the other hand, when the official-price subsample is used the values are considerably closer to the WTP. With a discount rate ranging from 5 to 10 percent, the expected energy savings are greater than the WTP, which may indicate that consumers undervalue energy efficiency or the so-called energy efficiency paradox exists. That is, even when investments in energy efficiency seem economically rational some consumers chose not to undertake them. Other reasons such as information barriers (not overcome by the labels), lack of liquidity (and/or credit) as well as uncertainty about future fuel prices might also contribute to explaining this result. Only with a discount rate of 15 percent is the WTP greater than the present value of fuel savings.

Galarraga et al. (2011b) also find some evidence of the energy efficiency paradox for the case of refrigerators in Spain. The paper estimates that the WTP is about one third of the energy savings that a consumer obtains during the lifetime of a refrigerator with the highest energy-efficiency label. 
Interestingly, independently of the values of the discount rate, the expected energy savings are relatively close to the WTP results obtained for cars using official prices. This can be interpreted as proof of the accuracy of the WTP estimated for energy-efficient vehicles using official prices, and the economic rationality of Spanish consumers when purchasing energy-efficient vehicles, that is, small presence of the energy efficiency paradox. The difference between the WTP and the present value of energy savings is significantly lower in the case of cars than in the case of refrigerators. This is probably due to the fact that the capacity of influencing on the future energy consumption on cars is much higher, and thus the potential of future savings are valued more.

\section{Conclusions}

Governments face growing pressure to limit energy-related emissions and consumption from an ever larger number of vehicles and from increasing car use. A mix of various policy instruments has been implemented to attain this general objective, such as taxes on fuel and car purchases, design standards and subsidies. These measures may be expanded and intensified given the major part played by transport in global energy consumption, and to tackle severe environmental problems. However, given the taste of consumers for more, larger and more powerful cars, and the potential limitations associated with some of the conventional regulatory instruments in this area, new approaches may be needed. In this sense, information programmes such as energy-efficiency labels may play an important role in both developed and emerging countries. Among other things, they may address the apparent lack of perception among consumers of the benefits of improved energyefficiency in cars. It is against this background that an EU energy-efficiency rating system for cars has been implemented, with labels ranging from $A$ (most energy efficient) to $G$ (least energy efficient).

In this paper, we use this labelling system to estimate the value that Spanish consumers place on energy-efficient cars. To estimate the implicit price of a high-rated car in terms of energy efficiency, i.e. the WTP of consumers for a car labelled A or B, we employ a database developed especially for this study with more than 3000 observations containing a rich set of characteristics of vehicles on the Spanish market. Besides official prices, the database incorporates a subsample of retail prices for 
cars obtained in situ through 'mystery shopping'. All this information is matched with the IDAE's official database information about vehicle energy-efficiency labels.

That database is used with a hedonic price approach to estimate a model of car prices that are set as function of different attributes of cars. Among other results, the paper reports a statistically significant coefficient of the variable that measures the effect of (very high) energy-efficiency labels: A and B labelled cars are found to be supplied at a price between 2.1 and 9.04 percent higher than that of similar but less energy-efficient cars, using two different price approximations (official listing and 'mystery shopping'). These results are first contrasted with alternative model specifications using fuel consumption and A-labelled vehicles. Subsequently, to evaluate the rationality of consumers, the results are compared with an approximation of the present value of energy savings. When official prices are used, the WTP for vehicles labelled as A is very close to the expected energy savings, which suggests that Spanish consumers rationally value energy efficiency in cars. When retail prices are used instead, the difference is quite substantial, which might indicate either an overestimation of the WTP in this case or a supply side distortion in the market due to aggressive commercial strategies of Spanish dealers. This question remains to be answered by future research. Using both official and retails prices seems promising area for further analysis as it offers new insights for coming research.

Before concluding the paper, we believe that it is important to set our results in the context of the recent literature on energy efficiency labelling in other goods. Energy efficiency certification systems are becoming a widespread tool for incentivising the purchase of products other than vehicles, including buildings and household appliances. Indeed, applying the hedonic price method to these other products provides similar results: products with high energy-efficiency labels are sold (or rented) at higher prices. For instance, Eichholtz et al. (2010) analyse the case of commercial buildings in the US, and find that rental (selling) rates associated with certified office buildings are 3 (16) percent higher per square foot than for similar but uncertified ones. These results are similar to those of Fuerst and McAllister (2011), who find that the price of commercial buildings in the US is 25 and 26 percent higher respectively for buildings with LEED and Energy Star certificates, while for rents the differences are +5 and +4 percent respectively. Again using the hedonic price method, Galarraga et al. (2011a) estimate the marginal price of energy-efficient dishwashers in Spain (those 
labelled $A$ or $A+)$, and find that the label explains as much as 15.6 percent of the price. Galarraga et al. (2011b) find that the figure is 8.9 percent for the case of the refrigerators market of the Basque Autonomous Community (Spain).

To sum up, we believe that this paper provides support for the use of information-based approaches in the area of energy and environmental regulation of transport, where measures are greatly needed. However, given that there are several significant policy instruments available to promote energy efficiency, it is very important to introduce such approaches with proper consideration for the synergies and negative interactions that they might bring about in such a context. Energy labels or certificates, on the other hand, could be used as the basis for designing other policy initiatives in this area, such as taxes levied on the energy inefficiency of the stock (Hanemann et al., 2012) or emission based car taxation (Rogan et al., 2011). The results of this article, and their possible derivations, may be particularly useful for an informed discussion of these and other policy issues in this important area. 


\section{References}

Achtnicht, M., 2012. German Car Buyers' Willingness to Pay to Reduce $\mathrm{CO}_{2}$ Emissions. Climatic Change, 113: 679-697.

Alberini, A., Filippini, M., Bareit, M., 2012. Price Premium for Energy Efficient Cars: A Hedonic Price Approach. Mimeo, ETH.

Arguea, N.M., Hsiao, C., 1993. Econometric Issues of Estimating Hedonic Price Functions with an Application to the U.S. Market for Automobiles. Journal of Econometrics, 56: 243-267.

Atkinson, S.E., Halvorsen, R., 1984. A New Hedonic Technique for Estimating Attribute Demand: An Application to the Demand for Automobile Fuel Efficiency. Review of Economics and Statistics, 66: 417-426.

Baltas, G., Saridakis, Ch., 2013. An Empirical Investigation of the Impact of Behavioural and Psychographic Consumer Characteristics on Car Preferences: An Integrated Model of Car Type Choice. Transportation Research Part A: Policy and Practice, 54: 92-110.

Caulfield, B., Farrell, S., McMahon, B., 2010. Examining Individuals Preferences for Hybrid Electric and Alternative Fuelled Vehicles. Transport Policy, 17: 381-387.

Chugh, R., Cropper, M., Narain, U., 2011. The Cost of Fuel Economy in the Indian Passenger Vehicle Market. Energy Policy 39: 7174-7183.

Court, A., 1939. Hedonic Price Indexes with Automotive Examples, in General Motors (ed.), The Dynamics of the Automobile Demand. GM corporation, New York.

Eichholtz, P., Kok, N., Quigley, J.M., 2010. Doing Well by Doing Good? Green Office Buildings. American Economic Review, 100: 2494-2511.

Espey, M., Nair, S., 2005. Automobile Fuel Economy: What is it Worth? Contemporary Economic Policy, 23: 317-323.

European Commission, 2000. Directive 1999/94/CE of the European Parliament and of the Council of 13 December 1990, relating to the availability of consumer information on fuel economy and $\mathrm{CO}_{2}$ emissions in respect of the marketing of new passenger cars.

European Union, 2011. EU Transport in figures. Publications Office of the European Union, Luxembourg.

Ewing, G., Sarigöllü, E., 2000. Assessing Consumer Preferences for Clean-fuel Vehicles: a Discrete Choice Experiment. Journal of Public Policy and Marketing, 19: 106-118.

Fuerst, F., McAllister, P., 2011. Green Noise or Green Value? Measuring the Effects of Environmental Certification on Office Values. Real Estate Economics 39: 45-69.

Galarraga, I., González-Eguino, M., Markandya, A., 2011a. Willingness to Pay and Price Elasticities of Demand for Energy-efficient Appliances: Combining the Hedonic Approach and Demand Systems. Energy Economics, 33: S66- S74. 
Galarraga, I, Heres, D. and González-Eguino, M., 2011b. Price premium for high-efficiency refrigerators and calculation of price-elasticities for close-substitutes: Combining Hedonic Pricing and Demand Systems. Journal of Cleaner Production, vol. 19, 2075-2081.

Griliches, Z., 1961. Hedonic price indexes for automobile: an econometric of quality change. Report of the Price Statistics Review Committee.

Griliches, Z., 1964. Notes on the Measurement of Price and Quality Changes. Studies in Income and Wealth, 28: 381-418.

Goodman, A.C., 1983. Willingness to Pay for Car Efficiency: A Hedonic Price Approach. Journal of Transport Economics and Policy, 17: 247-266.

Gago, A., Hanemann, M., Labandeira, X., Ramos, A., 2013. Climate Change, Buildings and Energy Prices, in Fouquet, R. (ed) Handbook on Energy and Climate Change. Edward Elgar, Cheltenham.

IPCC, 2007. Mitigation of Climate Change. Contribution of WGIII to the Fourth Assessment Report. Cambridge University Press, Cambridge.

Izquierdo, M., Licandro, O., Maydeu, A., 2001. Mejoras de Calidad e Índice de Precios del Automóvil en España. Estudios Económicos, 72. Servicio de Estudios del Banco de España, Madrid.

Kahn, J.A., 1986. Gasoline Price and the Used Automobile Market: A Rational Expectations Asset Price Approach. Quarterly Journal of Economics, 101: 323-340.

Kiso, T., 2010. Pricing Automobile Fuel Economy: A New Hedonic Approach. Working paper, Department of Agricultural and Resource Economics, University of Maryland.

Liu, Y., Helfand, G. E., 2012. A Hedonic Test of the Effects of Alternative Motor Fuel Act. Transportation Research Part A: Policy and Practice, 46 (10): 1707-1715.

Matas, A., Raymond, J.L., 2009. Hedonic Prices for Cars: An Application to the Spanish Car Market, 1981-2005. Applied Economics, 41: 2887-2904.

Ohta, M., Griliches, Z., 1983. Automobile Prices and Quality: Did the Gasoline Price Increase Change Consumer Tastes in the U.S.? NBER working paper 1211.

Pérez, P., Monzón, A., 2008. Consumo de Energía por el Transporte en España y Tendencias de Emisión. Observatorio Ambiental, 11: 127-147.

Proost, S., Van Dender, K., 2012. Energy and Environment Challenges in the Transport Sector. Economics of Transportation, 1: 77-87.

Reis, H.J., Santos Silva, J.M., 2002. Hedonic Price Indexes for New Passenger Cars in Portugal (1997-2001). Working Paper, 10-02. Banco de Portugal.

Rogan, F., Dennehy, E., Daly, H., Howley, M., Ó Gallachóir, B.P., 2011. Impacts of an Emission Based Private Car Taxation Policy. First Year Ex-post Analysis. Transportation Research Part A: Policy and Practice, 45(7): 583-597.

Rosen, S., 1974. Hedonic Prices and Implicit Markets: Product Differentiation in Pure Competition. Journal of Political Economy, 82: 34-55. 
Van der Vooren, A., Alkemade, F., Hekkert, M.P., 2013. Environmental Performance and Firm Strategies in the Dutch Automotive Sector. Transportation Research Part A: Policy and Practice, 54: 111-126.

Wooldridge, J. E., 2009. Introductory Econometrics: A Modern Approach. South-Western, Mason. 


\section{APPENDIX A}

\section{Mandatory label}

\section{Description of fuel consumption and $\mathrm{CO}_{2}$ emissions labels}

1. In the Spanish territory, fuel consumption and $\mathrm{CO}_{2}$ emissions labels must have the following format:

A guide containing fuel consumption and $\mathrm{CO}_{2}$ emissions together with a detailed description of all new vehicles models' characteristics can be obtained at all points of sale by free.

Commercial brand/model:

Fuel type:

\begin{tabular}{|c|c|}
\hline \multicolumn{2}{|c|}{$\begin{array}{l}\text { Official consumption } \\
\text { (ACCORDING TO THE TERMS OF THE DIRECTIVE 80/1268/CEE) }\end{array}$} \\
\hline Kind of driving & $\mathrm{L} / 100 \mathrm{Km}$. \\
\hline \multicolumn{2}{|l|}{ In the city } \\
\hline \multicolumn{2}{|l|}{ On the road } \\
\hline \multicolumn{2}{|l|}{ Weighted average } \\
\hline \multicolumn{2}{|c|}{$\begin{array}{c}\text { OFFICIAL SPECIFIC } \mathrm{CO}_{2} \text { EMISSIONS } \\
\text { (ACCORDING TO THE TERMS OF THE DIRECTIVE 80/1268/CEE) }\end{array}$} \\
\hline \multicolumn{2}{|c|}{$\mathrm{g} / \mathrm{Km}$. } \\
\hline
\end{tabular}

Fuel consumption and $\mathrm{CO}_{2}$ emissions depend not only on vehicles' performance; driving behavior as well as other no technical factors also influence them. $\mathrm{CO}_{2}$ is the main

component of the greenhouse gases, which are responsible for the global warming.

Source: Royal Decree 837/2002 


\section{Voluntary label}

\section{Energy Efficiency}

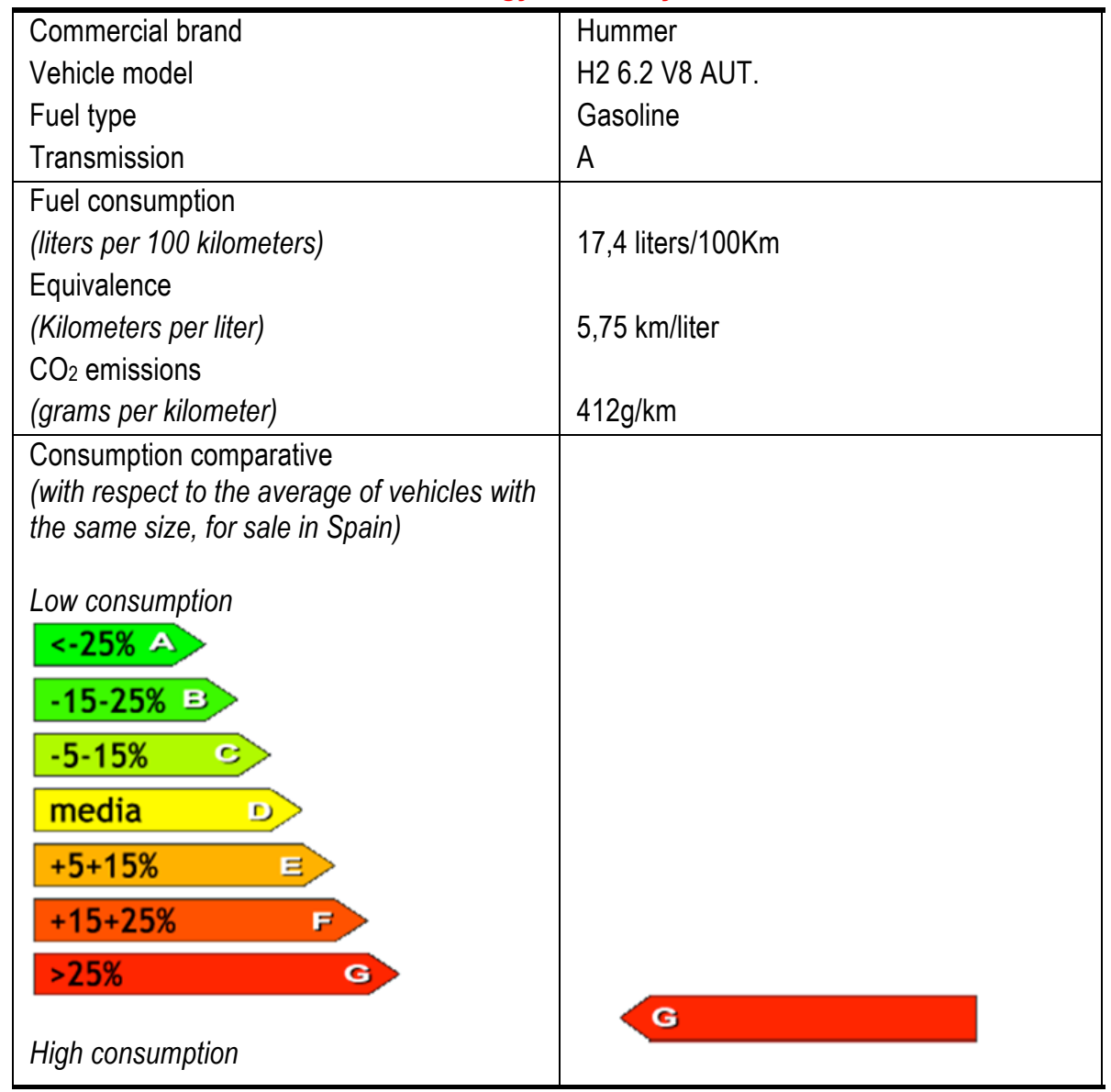

Valid until 02/12/2010

$>$ A guide containing fuel consumption and $\mathrm{CO}_{2}$ emissions together with a detailed description of all new vehicles models' characteristics can be obtained at all points of sale by free.

> Fuel consumption and $\mathrm{CO} 2$ emissions depend not only on vehicles' performance; driving behavior as well as other no technical factors also influence them. CO2 is the main component of the greenhouse gases, which are responsible for the global warming.

Source: Royal Decree 837/2002 


\section{APPENDIX B}

Table B.1. Description of Dummies

\begin{tabular}{|c|c|c|c|}
\hline Characteristic & \multicolumn{3}{|l|}{ Description } \\
\hline D1. Type of fuel & \multicolumn{3}{|c|}{$\begin{aligned} 1 \text { dummy } & =1 \text { if Gasoline } \\
& =0 \text { if Diesel }\end{aligned}$} \\
\hline D2. Commercial segment & \multicolumn{2}{|c|}{11 dummies for commercial segment: } & $\begin{array}{l}\text { Big sedan } \\
\text { Small sedan } \\
\text { Sport } \\
\text { Luxury } \\
\text { Mini } \\
\text { Big minivan } \\
\text { Medium minivan } \\
\text { Small (Reference) } \\
\text { Big Four-wheel-drive } \\
\text { Medium Four-wheel-drive } \\
\text { Small Four-wheel-drive }\end{array}$ \\
\hline D3. Brand & \multicolumn{3}{|c|}{$\begin{array}{l}32 \text { dummies for the } 32 \text { most representative brands on the Spanish market } \\
\text { for light-duty vehicles }\end{array}$} \\
\hline D4. Number of seats & 7 dummies for & \multicolumn{2}{|c|}{$\begin{array}{l}2 \text { seats } \\
4 \text { seats } \\
5 \text { seats (Reference) } \\
6 \text { seats } \\
7 \text { seats } \\
5 \text { seats convertible in } 7 \\
2+2 \text { seats } \\
\end{array}$} \\
\hline D5. Number of Airbags & 5 dummies for & \multicolumn{2}{|c|}{$\begin{array}{l}2 \text { airbags (Reference) } \\
4 \text { airbags } \\
5 \text { airbags } \\
6 \text { airbags } \\
7 \text { airbags }\end{array}$} \\
\hline D6. Number of gears & 4 dummies for & \multicolumn{2}{|c|}{$\begin{array}{l}5 \text {-speed gearbox (Reference) } \\
6 \text {-speed } \\
7 \text {-speed } \\
\text { Automatic }\end{array}$} \\
\hline D7. Drive system & 3 dummies for & \multicolumn{2}{|c|}{$\begin{array}{l}\text { Front-wheel drive (Reference) } \\
\text { Rear-wheel drive } \\
4 \times 4\end{array}$} \\
\hline \multicolumn{4}{|l|}{ D8. Extra equipment } \\
\hline Air Conditioner $(\mathrm{A} / \mathrm{C})$ & \multicolumn{3}{|c|}{$1=$ yes $/ 0=$ no } \\
\hline Electronic stability control & \multicolumn{3}{|c|}{$1=$ yes $/ 0=$ no } \\
\hline $\operatorname{Rim}$ & \multicolumn{3}{|c|}{$1=$ yes $/ 0=$ no } \\
\hline Navigation system & \multicolumn{3}{|c|}{$1=$ yes $/ 0=$ no } \\
\hline Xenon arc lamps & \multicolumn{3}{|c|}{$1=$ yes $/ 0=$ no } \\
\hline Parktronic & \multicolumn{3}{|c|}{$1=$ yes $/ 0=$ no } \\
\hline
\end{tabular}

Source: The authors. 